\title{
Die beraubte Fabel (1748)
}

Es zog die Göttinn aller Dichter, Die Fabel, in ein fremdes Land, Wo eine Rotte Bösewichter Sie einsam auf der Straße fand.

Ihr Beutel, den sie liefern müssen, Befand sich leer; sie soll die Schuld Mit dem Verlust der Kleider büssen, Die Göttinn litt es mit Geduld.

Hier wies sich eine Fürstenbeute, Ein Kleid umschloß das andre Kleid; Man fand verschiedner Thiere Häute, Bald die, bald jene Kostbarkeit.

Hilf Himmel, Kleider und kein Ende! Ihr Götter! schrien sie, habet Dank; Ihr gebt ein Weib in unsre Hände, Die mehr trägt, als ein Kleiderschrank.

Sie fuhren fort, noch mancher Plunder Ward preis; doch eh man sichs versah, $\mathrm{Da}$ sie noch schrien, so stund, o Wunder! Die helle Wahrheit nackend da.

Die Räuberschaar sah vor sich nieder, Und sprach: Geschehen ist geschehn, Man geb ihr ihre Kleider wieder, $\mathrm{W}^{\prime}$ er kann die Wahrheit nackend sehn?

\section{GotTHOLd EpHRAIm Lessing}

Von dem Wesen der Fabel (1759) (Auszug)

Jede Erdichtung, womit der Poet eine gewisse Absicht ver30 bindet, heißt seine Fabel. So heißt die Erdichtung, welche er durch die Epopee, durch das Drama herrschen läßt, die Fabel seiner Epopee, die Fabel seines Drama.

Von diesen Fabeln ist hier die Rede nicht. Mein Gegenstand 